The investigations are being continued with different gases and different wall materials.

Physical Laboratory of the

R. M. SIEvert.

'Radiumhemmet',

Stockholm, March 15 .

1 J. W: Broxon, Phys. Rev., 37, 1320 ; 1931

2 G. T. P. Tarrant, Proc. Roy. Soc. A, 135, 223 ; 1932

${ }^{3}$ E. G. Steinke and H. Schindler, Naturwiss., 20, 15; 1932.

4 R. M. Sievert, Acta Radiol, 12, 190; 1931.

5 G. Jaffé, Ann. Phys., 25, 257; 1908: and 42, 303 ; 1913.

E. Stahel, Strahlenther., 31, 582; 1929 .

'A. H. Compton, R. D. Bennet, and J. C. Stearns, Phys. Rev., 38, $1565 ; 1931$.

\section{Heterospory and the Angiosperms}

For many years it has been generally assumed by botanists that in Angiosperms, as in the heterosporous Pteridophytes, the megaspores are larger than the microspores. In a study of megaspore development in Enothera rubricalyx (Gates and Sheffield), ${ }^{1}$ it was incidentally discovered that this is not the case. Series of measurements showed that the corresponding absolute values were about $4930 \mu^{3}$ for the "megaspore ' mother-cell and $12,630 p^{3}$ for the 'microspore' mother-cell at the end of meiosis. The need for comparative measurements of the size of the spores in the pollen and ovules of various plants was pointed out, and brief reference was made to the possible significance of the above condition.

It has since been found that this subject has been independently discussed at some length by Prof. R. B. Thomson, ${ }^{2}$ who has also made measurements of spore size in various Pteridophytes, Gymnosperms, and Angiosperms. He finds that in some Cycads, Conifers, and Angiosperms the pollen spore is larger than the seed spore, while in others the reverse is the case.

There is then at present no certainty that the Angiosperms were derived from heterosporous ancestors. That the microspores are larger than the megaspores in Enothera, Pontederia, and Typha, while they are smaller in Lilium, may be a local development in each case. It is to be expected that the morphological and biological relations within the flower, such as size of ovule and length of style, will be factors in adjusting the relative size of the spores which produce respectively the male and female gametophyte. Thus in Enothera the need for a long pollen tube necessitates storage of food material in the pollen mother-cell. This is abundantly present in the cytoplasm and helps to account for the large size of the cell. In the ovule, on the other hand, food storage occurs not in the megaspore mother-cell but especially in the chalazal region of the nucellus.

Thomson proposed the term heterangy for the condition in seed plants where the megaspore is retained within the megasporangium (ovule), confining the term heterospory to those forms in which the megaspores are discharged. Thus the ancestor from which seed-plants (Pteridosperms) arose might have been heterosporous in the sense in which the term is used in Selaginella and other Pteridophytes, or it might equally well have been homosporous but heterangious. Equisetum well represents an earlier condition, homosporous, homangious, with the gametophytes developing externally to the spores. From such a condition, seed plants showing heterangy and an intrasporal female gametophyte might have developed.

It is well known that although Equisetum is homosporous, some of the spores produce a male gametophyte and some a female. The latter may, however, sometimes develop antheridia as well as archegonia, although it does not appear to be known whether the male gametophyte ever produces archegonia. The fact that the female gametophyte may produce both types of sex organs indicates that the separation of sex tendencies in meiosis in Equisetum is not absolute. Hence it would probably be futile to look here for sex chromosomes. Nevertheless, it may be that nuclear differentiation is responsible for the fact that some spores of Equisetum produce a male and some a female gametophyte. It needs to be definitely determined whether two spores of each tetrad are male and two female in tendency. If this were so, the differentiation might have resulted from an endosporal chromosome mechanism for sex determination similar in its main features to that which is known in certain Liverworts and in certain diœcious flowering plants, but less fully developed.

It may be pointed out that such a nuclear differentiation of homospores would involve an evolutionary process of quite a different nature from that which has given rise to the differentiated megasporangia and microsporangia of Selaginella. It is difficult to see how these two processes could have taken place even successively in the same series of organisms. Thus the heterospory in Selaginella could not have been superposed upon the condition found in Equisetum if the latter is a case of morphological homospory but with the spores of each tetrad separated as to sex. On the other hand, if the separation of spore types in Equisetum is only a partial one, environmentally controlled, it may have been brought about by the same kind of evolutionary process as has produced the differentiation of microspores and megaspores in Selaginella.

The differentiation, in the same cone, of microsporangia and megasporangia containing spores which develop their respective gametophytes, as in Selaginella, is a somatic differentiation which is completely independent of the meiotic divisions. It could not have been preceded by spore differentiation of a type in which the sex potentialities of the spores in each tetrad are separated. How the condition in Equisetum was derived in turn from that in the homosporous leptosporangiate ferns, in which each spore produces a gametophyte bearing both male and female sex organs, we do not know.

Thus it appears that the ancestral seed plants were derived from forms which developed heterangy, but not from homosporous forms with sex potentialities separated in meiosis. Whether they had megaspores and microspores seems quite uncertain. Perhaps descendants of the modern eusporangiate ferns might lay claim to represent such a group. Since, however, the relative sizes of the male and female spores in different families of Angiosperms can vary so widely, there seems no adequate reason at present for denying that the group may have been derived from ancestors which showed heterospory. The sporangium is so closely related to its enclosed spores that differentiation of sporangia as an evolutionary process must be closely connected with differentiation of spores. This means heterospory in the etymological sense, although not necessarily in the sense in which that term is commonly used.

A large and interesting field regarding the relative sizes of the spores in Angiosperms, their evolutionary relationships, and their relations to various features in the biology of the species, here awaits investigation.

King's College,

R. Ruggles Gates.

University of London, April 17.

1 Gates and Sheffield, "Megaspore Development in Enothera rubricalyx ", Proc. Roy. Soc., B, 105, 499 ; 1929.

"Thomson, R. B., "Evolution of the Seed Habit in Plants" Trans. Roy. Soc. Can., 21, 229; 1927.

No. 3265, VoL. 129] 